\title{
An Examination of Murder and Suicide in Guyana
}

\author{
Paulette Andrea Henry \\ Department of Sociology, University of Guyana \\ 95 Amsville Housing Scheme, New Amsterdam, Berbice, Guyana \\ Tel: 592-650-7855/333-2097 E-mail: phenryugbc@yahoo.com
}

Received: January 18, 2016 Accepted: March 13, 2016 Published: June 11, 2016

doi:10.5296/iss. v4i1.8892

URL: http//dx.doi.org/10.5296/iss.v4i1.8892

\begin{abstract}
In addition to being remembered in what became known as the "Jonestown Massacre," where more than 900 members of an American cult died in a mass suicide-murder under the direction of their leader in 1978, Guyana continues to receive global and local attention for the prevalence in suicide. The 2014 WHO report named Guyana as the country with the highest suicide rate per capita globally with recent suicide statistics showing 272 reports over a thirty-month period.

Recently, the incidence of murder suicide has gained a lot of media attention, and seems to be linked to "crimes of passion" or intimate partner conflict, with men very often being the perpetrators. Particularly, East Indian men and young men are more prone to commit suicide, Through the analysis of both police and media reports and other literature, this study uses mixed methodologies in analyzing the number of murder -suicide over the last five years, characteristics of the perpetrators inclusive of ethnicity, relationships between killers and victims and the method used in the deaths in Guyana. The study paves the way for more in-depth analysis of the phenomenon. Finally, the paper concludes with a presentation of its findings and possible recommendations.
\end{abstract}

Keywords: murder-suicide, characteristics, intimate partner relationships, method of choice 


\section{Macrothink}

\section{Introduction}

The 2014 World Health Organization (WHO) report names Guyana as the country with the highest suicide rate per capita, and the trend seems to be continuing in 2015 with recent suicide statistics showing 272 reports over a thirty- month period (Guyana Stabroek News, 2015). According to the latest WHO data published in May 2014, suicide deaths in Guyana reached 277 or $4.90 \%$ of total deaths. Moreover, according to the World Health Rankings, the age adjusted Death Rate is 43.22 per 100,000 of population ranks Guyana at number 1 in the world. These findings strongly reinforce the conclusions drawn by Henry (2015) from an analysis of the suicide trends in Guyana during the period 1988 to 2009 which showed that annual reported cases of suicide, if left unmonitored, could increase to more than 300 by the year 2025, with an annual average number of approximately 272 cases of suicide deaths for the period 2016-2025. (See Figure 1)

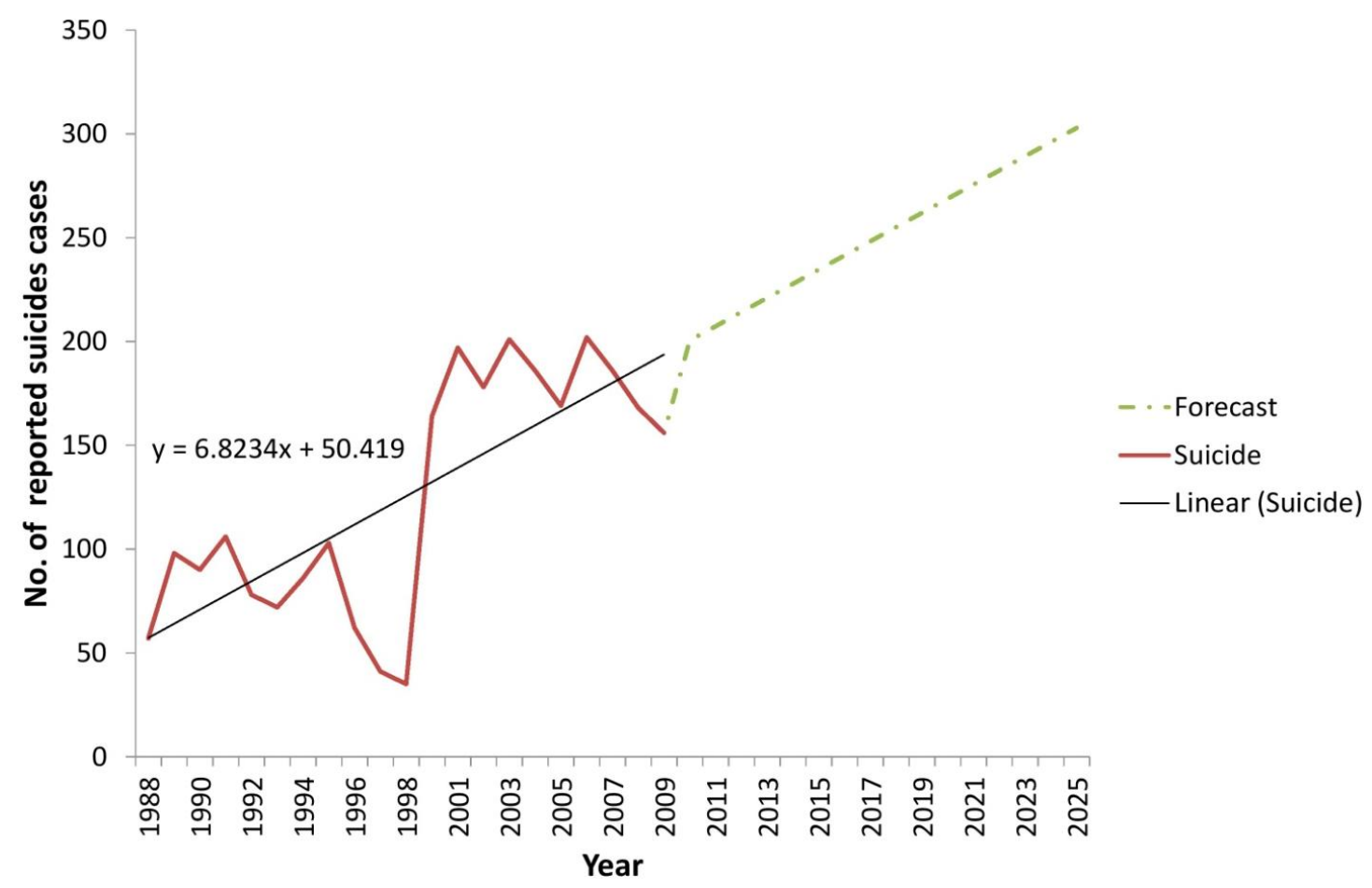

Figure 1. Current and projected suicide trends in Guyana

Source: Henry, 2015

Although it has been established that suicide levels are high, both globally and locally, data on homicides- suicides (H-S), popularly known as murder- suicide, is low. The only unprecedented incidence of murder suicide was the Jonestown massacre in 1978 which occurred in the hinterlands of Guyana where an American cult leader brought his followers to Guyana and upon interventions of the American government, he led a mass murder suicide intervention which resulted in the loss of over 900 American lives, inclusive of officials of the American government and the cult leader. 
In the Caribbean, published scholarship on the phenomenon of $\mathrm{H}-\mathrm{S}$ is lacking. However, anecdotal evidence, mostly from media sources, has raised public awareness of these disturbing occurrences (Emmanuel and Campbell, 2012). Available literature shows that nearly one in seven homicides worldwide involve the killing of an intimate partner. Moreover, men who kill their intimate partners tend to be in their mid- to late-30s and, on average, older than those who perpetrate nonfatal intimate partner violence (IPV) those who kill other family members, and those who kill nonfamily members (Kivisto, 2015). Earlier works of Barraclough and Harris, (2002) also found that the homicide perpetrator and victim is positively associated with the perpetrator's risk for subsequent suicide with IPH perpetrators exceeding 30 percent, but, notably, these extreme rates appear specific to male perpetrators.

Significantly, murder-suicide seems to be inherently linked to emotional relationships in Guyana. Studies in the Caribbean seem to support this perception since in their examination of homicide -suicide (H-S) in the Caribbean, Emanuel and Campbell (2012) found that the reasons reported for the $\mathrm{H}-\mathrm{S}$ almost always involved intimate-partner relationship conflict, often in the context of the woman threatening to end or leave the relationship. Addressing the causation of suicide in Trinidad and Tobago, it was found that lover's quarrels, interpersonal problems, religious beliefs, cultural rigidity, marginalization, ethnic disadvantage, poverty, family problems and depression have been stated as precipitating causes of suicidal behaviour among Indo-Trinidadians (Maharaj and Abdool, 2005). The writers also suggested that the incidence of suicide was linked to culture and have indicated that a great deal of research needs to be performed on a global scale to ascertain the degree to which culture impacts on suicidality and this in turn can be used to address the rising rates of these self-destructive behaviours since culture provides coping strategies for individuals. As civilization advances many of these coping mechanisms are lost, unclothing the genetic predisposition of vulnerable groups. It is proposed that in the management of suicidal behaviour, a system of therapeutic re-culturation is needed with an emphasis on relevant culture- based therapies. Additionally, looking at this intimate partner relations which lead to suicide, Daly et al (1992) suggest that social psychological studies of "normal" jealousy and psychiatric studies of "morbid" jealousy both suggest that male and female jealousy are qualitatively different in ways consistent with theoretical predictions. These writings will be used in analyzing the complexities of murder suicide in Guyana.

\section{Media Reporting of Suicide}

Much of the data and perspectives on murder suicide were drawn from media reports. Maharajh et al (2005) stated that there are no guidelines for the reporting of suicides in Trinidad and other Caribbean countries. Suicide reports in the media are often sensationalized with graphic descriptions in headline coverage. There is the depiction of live televised suicides and homicides which the author posits may be contributory to the high suicidal rates. It is also felt that another contributory factor may be the viewing of popular Hindi films that often depict maladaptive methods of handling personal, family and stressful situations. For Guyana, this would need further analysis before one can make such an assessment; nonetheless Indian movies seem to be very popular within the East Indian community. 


\section{Macrothink}

Issues in Social Science

ISSN 2329-521X 2016, Vol. 4, No. 1

However, the essential point is that evidence of $\mathrm{H}-\mathrm{S}$ in the Caribbean relies mainly on anecdotal press reports rather than results of formal inquests (Emanuel, 2012).

\section{Research Methodology}

Much of the data for this article was collected from police records during the period 2009 to 2015, WHO reports as well as media reports. A quantitative approach was conducted in the analysis of these records and inferences drawn. Police records appropriately sourced from the police registry, provided more detailed analysis of murder suicide by gender, age, ethnicity and method used. Media reports on the other hand provided additional information and anecdotes from the family and community members pertinent to the characteristics of the perpetrators and the victims, the relationships between perpetrators and victims as well as the method used.

\section{Findings}

\subsection{Demographic Data}

\subsubsection{Age}

Police data show that 22 murder-suicides were committed between the years 2009 to 2015 , with the largest occurrence ( 7 or 31.8 percent) in 2013. Table 1 (Note 1) outlines the murder suicide by age categories. The highest number of murder-suicide deaths occurs among the 20-49 age-group (Figure 2). The 20-29 age category attracts the highest percentage of perpetrators $(41 \%)$, followed by the 30-39 age group (28\%) percent and the least incidents being within the under 15 and the over 50 age groups. The data shows that the majority of persons who commit murder suicide $(73 \%)$ are less than 40 years old. The findings for murder-suicide are not dissimilar from the general findings on suicide which shows that suicide in Guyana is largely committed by younger persons. It was the leading cause of mortality among individuals from 15-24 years old and the third leading cause of death among those 25-44-years old (PAHO/WHO, 2012).

Table 1. Murder -suicide in Guyana by age categories

\begin{tabular}{lcc}
\hline Age & Perpetrators & Percentage \\
\hline Below 15 & 0 & 0 \\
$15-19$ & 1 & 4.5 \\
$20-29$ & 9 & 41 \\
$30-39$ & 6 & 27 \\
$40-49$ & 5 & 23 \\
Over 50 & 1 & 4.5 \\
Total & 22 & 100.0 \\
\hline
\end{tabular}




\section{Macrothink

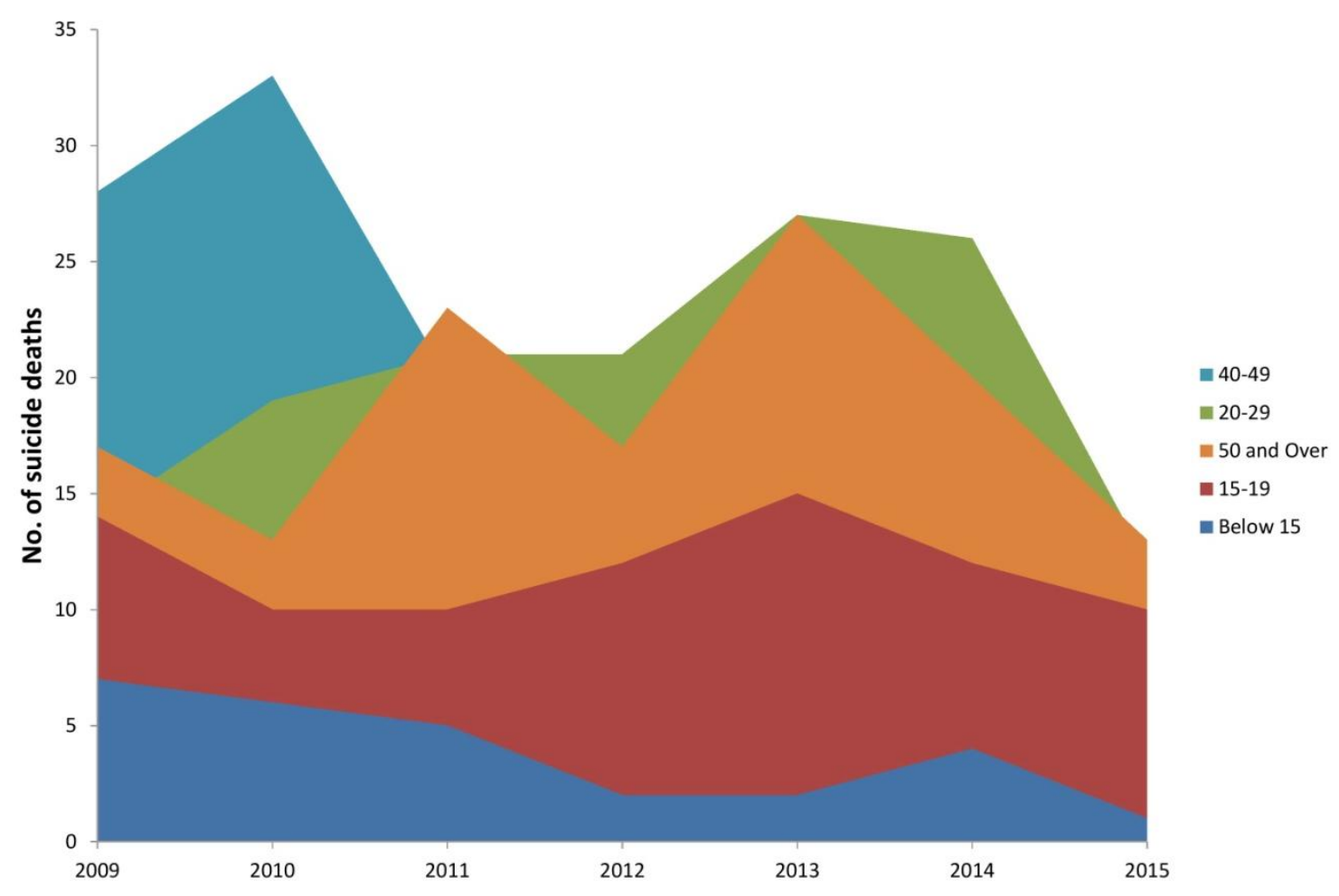

Figure 2. Age-ranges of murder-suicide victims

\subsubsection{Gender}

The findings show that the perpetrators were all male whilst the victims, except in two cases, were all female. According to the latest WHO data published in 2013, life expectancy in Guyana is: Male 60.1 , female 67.0 and total life expectancy is 63.5 which gives Guyana a World Life Expectancy ranking of 149. With the increase in male suicides in Guyana, this may impact the life expectancy of males. This further alludes to the disparity in the emotional capacity of genders in managing stress, depression and more particularly, intimate partner relationships in the aftermath of infidelity.

\subsection{Murder-suicide Trend}

When murder-suicide was juxtaposed to the national data on suicide, the data show that for every year group, murder -suicide was a small fraction of the national statistics (Figure 3). Looking at the statistics from WHO and the Guyana Police Force over a three-year period as shown in Figure 3, the deaths due to murder- suicide record a small percentage. 


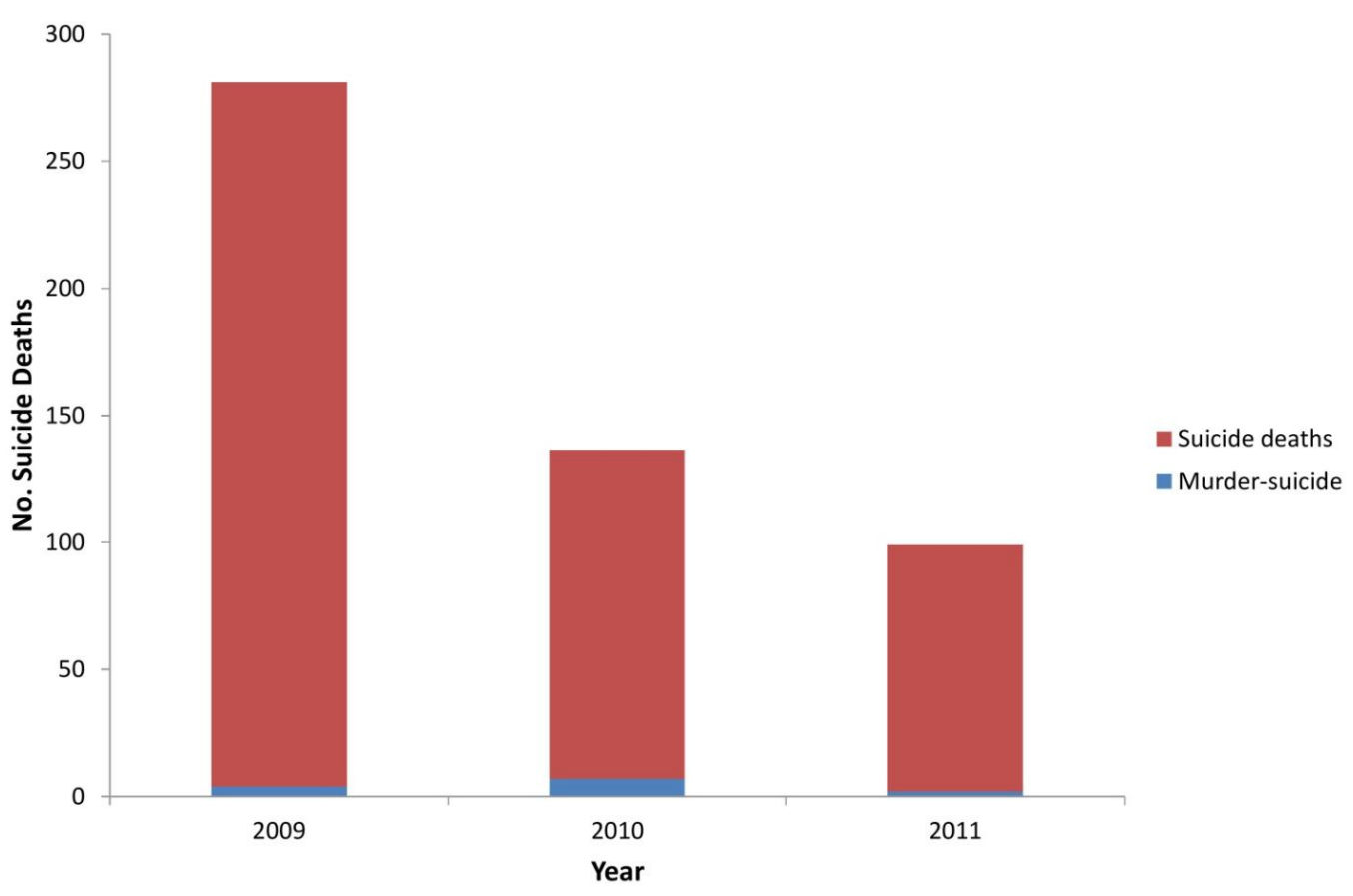

Figure 3. Comparison of murder-suicide deaths and national suicide deaths in Guyana

\subsubsection{Current and Project Trends in Murder-suicide}

An analysis of suicide deaths from records of the Guyana Police Force (GPF) for the period 2009-2015 shows an increasing trend in the number of murder-suicide deaths (Figure 4 Adapted from the Guyana Police Force database). Murder-suicide deaths peaked in 2013, whilst 2010 recorded the lowest number of murder-suicide cases over the period.

A projection of murder-suicide deaths based on the 2009-2015 trends predicts annual average number of murder-suicide deaths of five for the period 2016-2030, with a projected total of 76 over the 15-year period (Figure 5). This shows a consistent increase of at least one dual fatality between the years 2016 to 2019, and two between the years 2066-2030. This finding further confirms Henry (2015) whose projection points to an increase, of which murder-suicide will add to this projection. 


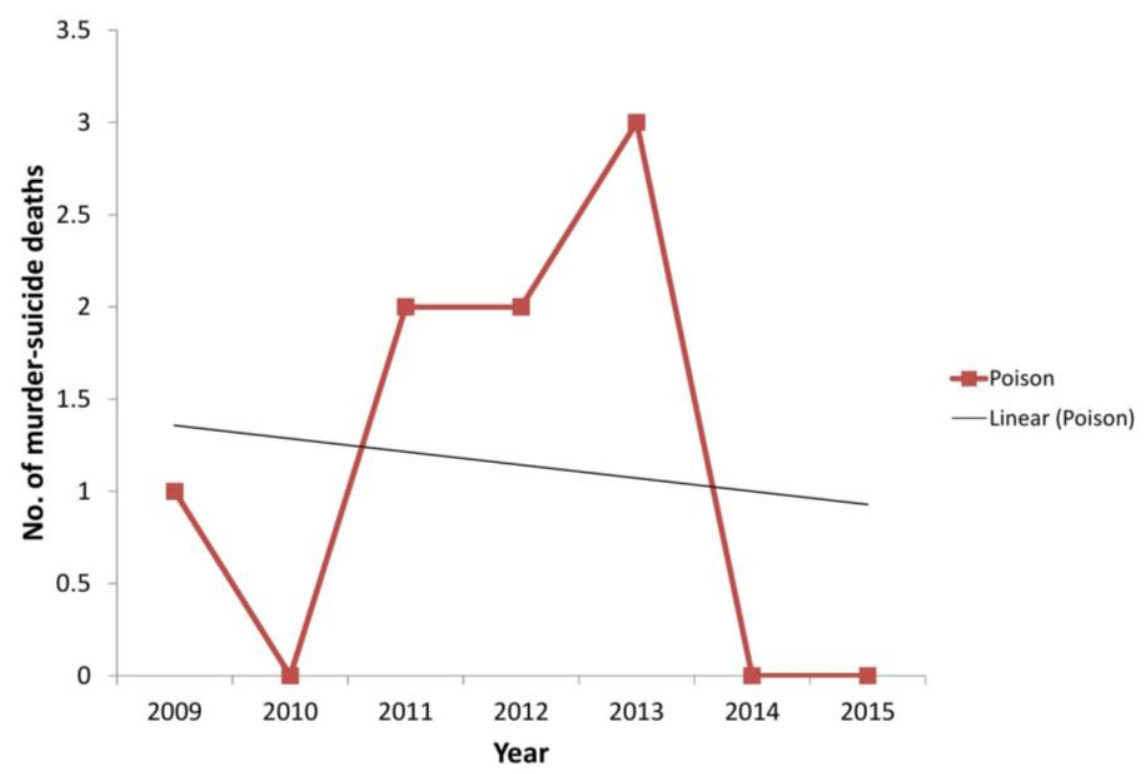

Figure 4. Total number of reported murder-suicide deaths for the period 2009-2015 Source: Records of the Guyana Police Force, 2015

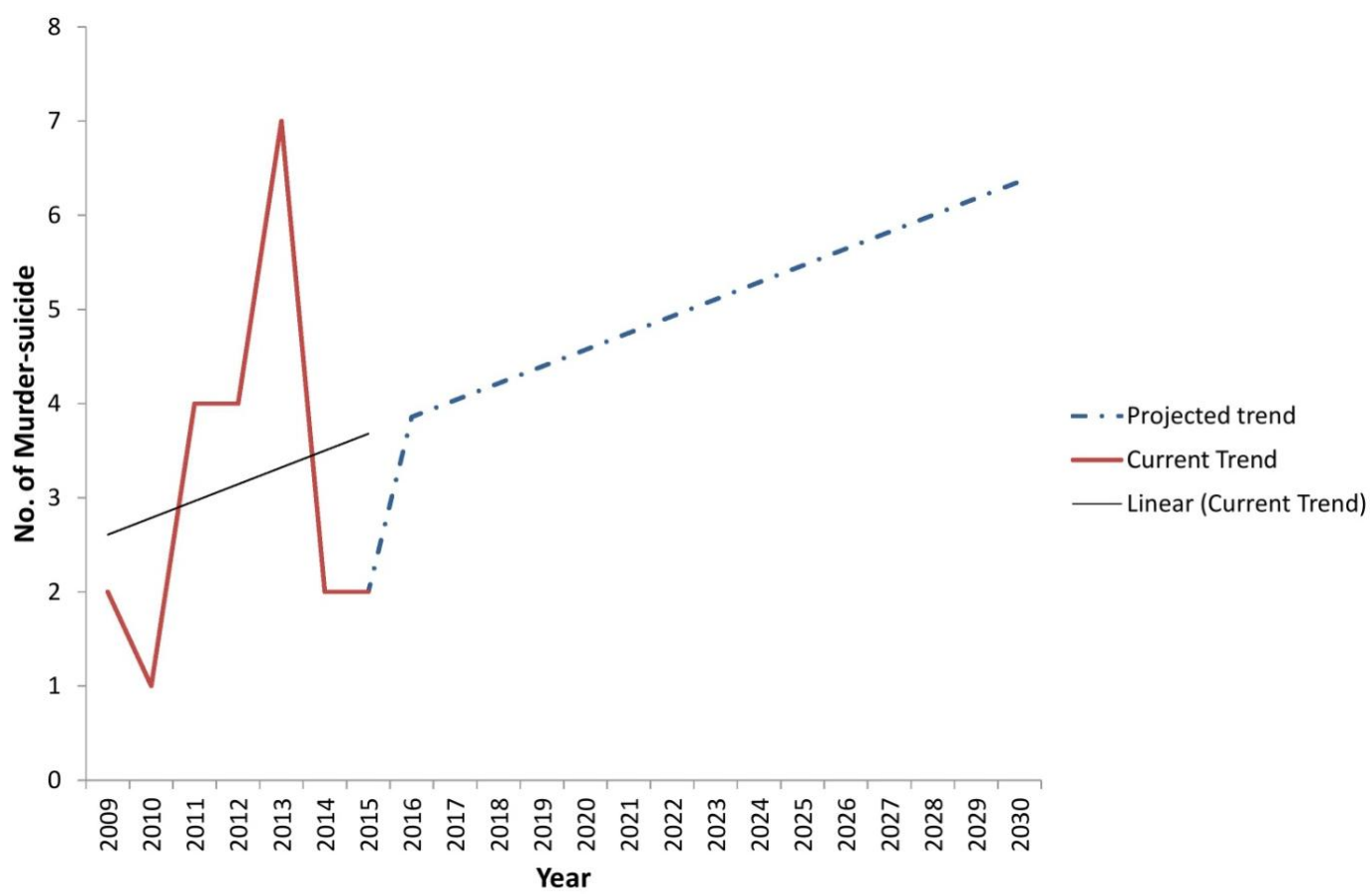

Figure 5. Project trends in murder-suicide in Guyana for the period 2016-2030

\subsection{Method of Choice}

An analysis of the methods of choice in murder-suicide deaths shows that poisoning, hanging, shooting and stabbing were the suicide methods used during this period (Figure 6). 


\section{Macrothink}

Poisoning was one of the leading methods in suicide deaths, which is second only to hanging which accounted for $41 \%$ of suicide deaths during the period. From 2009-2015 more than $36 \%$ of all reported suicide/murders was as a result of poisoning. Poisoning could easily be seen as the preferred method because of ease of access to pesticides. Henry (2015) pointed out the increase of availability of pesticides in every region in Guyana with very limited controls for procurement could contribute to this preferred method of choice.

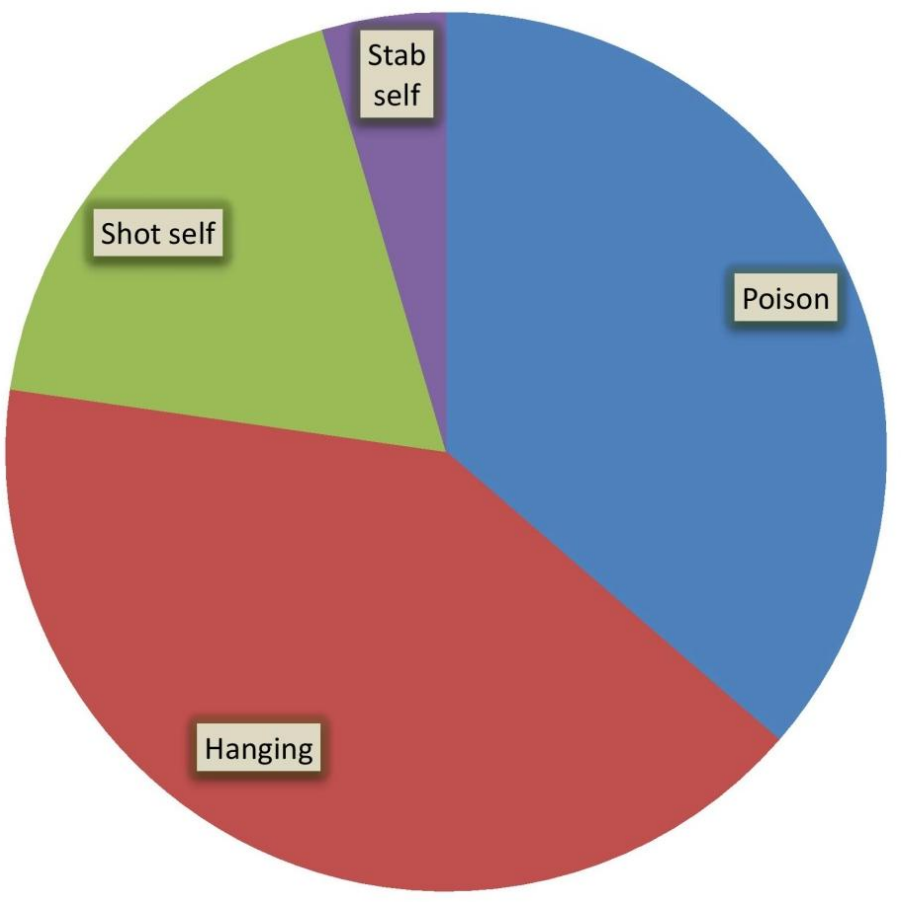

Figure 6. Methods of choice in murder-suicides in Guyana

An increasing trend was observed in suicide deaths in all categories, with the exception of suicide by poisoning, where a decreasing trend was observed over the period (Figure 7 and Figure 8). The decrease in the number of murder-suicide deaths through poisoning may have been a result of the introduction of legislation in 2010 which controls access to pesticides which are often the primary substances used in suicide deaths. The decrease in suicide deaths from poisoning is compensated by a corresponding increase in more contemporary methods used in murder-suicides (Henry, 2015). 


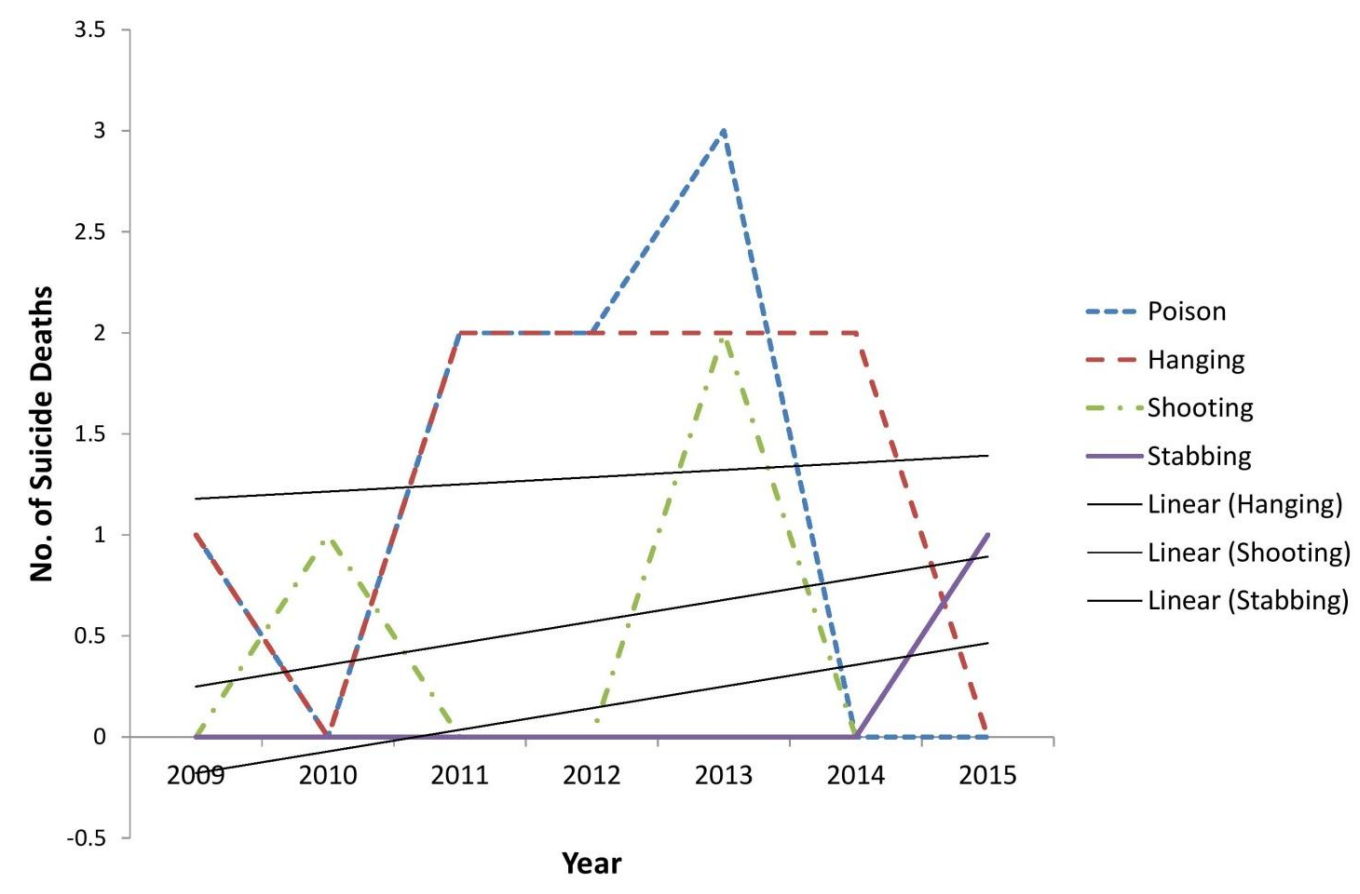

Figure 7. Methods of murder-suicide from 2009 to 2015

Source: Guyana Police Force, 2015

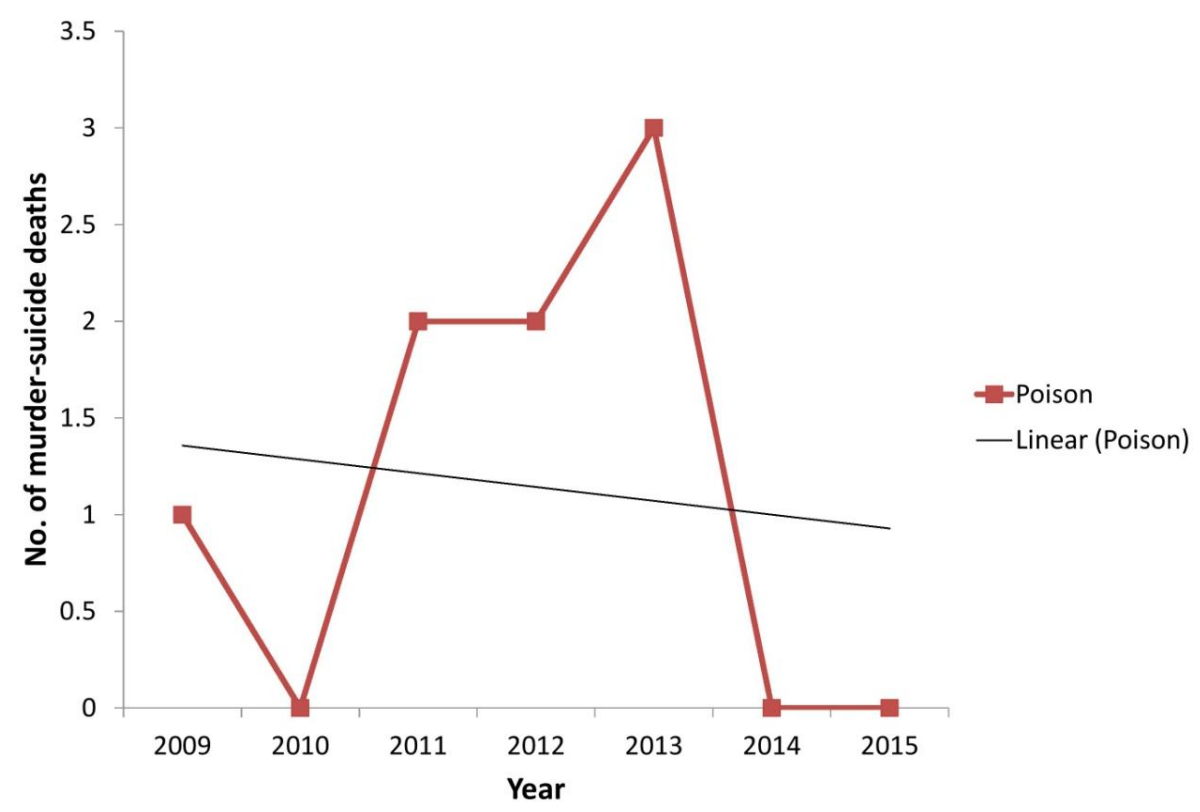

Figure 8 . Number of reported murder-suicide deaths due to poisoning for the period 2009-2015 


\subsection{Characteristics of Perpetrators: Media Analysis}

Earlier writers pointed to the intimate partner relations between perpetrators and victims as one of the primary characteristics of perpetrators of murder-suicide (Emanuelle, 2012). This was consistent with the findings in Guyana where except for one person in the study, all of the perpetrators were engaged in an intimate relationship with the victim, the majority were young and predominantly of East Indian ancestry. Whist debates in media articles suggest that the East Indian perpetrators were more likely to be Hindus; there is no conclusive evidence to this report other than anecdotes. This would warrant further investigation on religious influence and suicide. Additionally, as drawn from media reports, many of the relationships seemed to have a history of domestic violence or infidelity and lead to emotional outbursts resulting in murder-suicide. In sum as gathered from a small study undertaken in one rural community, perpetrators and victims were likely to be poorly-educated, employed in low-income occupations, residing in the same community all their lives and to be less likely to have children. Resultantly, the Guyana situations show that these emotional outbursts which lead to fatalities have all been carried out by males and tend to suggest that men may not know how to cope with stressors which may accompany intimate relations thereby continuing to record the highest percentages of suicidal fatalities.

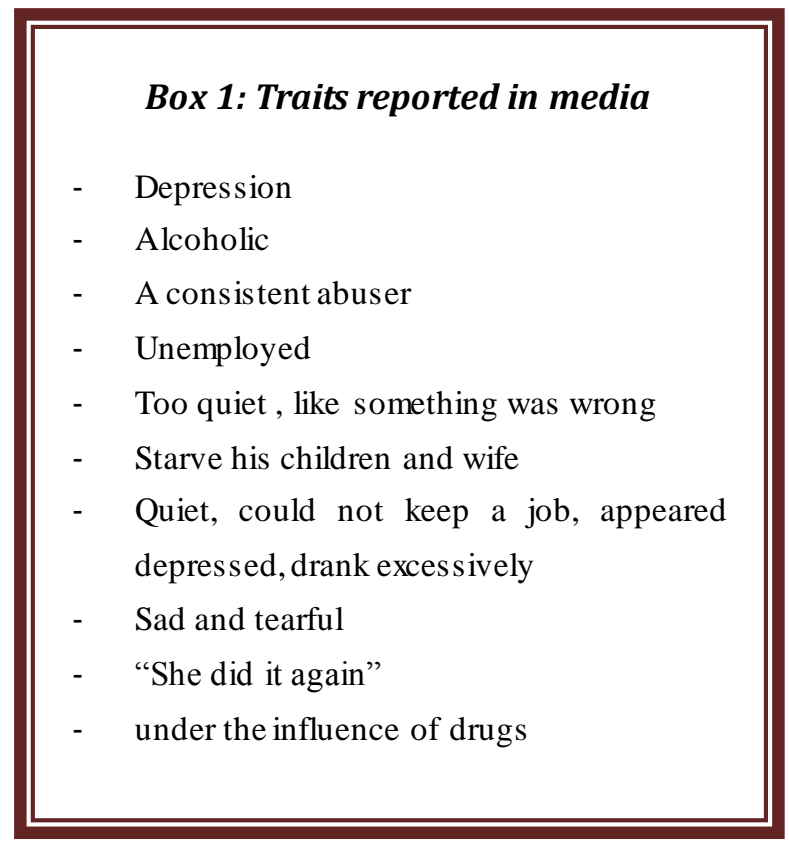

Depression or behaviours as sociated with depression have been cited as another characteristic displayed by persons prior to inflicting these fatal acts on themselves and others. Whilst no clinical diagnosis informed the reports of depression, family and community reports point to the perpetrators displaying sadness, outbursts of anger, periodic quietness, reports of betrayal and disappointment with their partner. These behaviours suggest that depression, an element of mental health is a factor that must be addressed within the public health spectrum in Guyana. 
Of note is that although murder-suicide represents a very low percentage of the national statistics, media tends to capture the attention of readers and push the issue to the forefront of the news reports and other forms of social media. Some of the titles within the local Guyanese media that riveted attention on the issue are found in the box below:

\author{
Box 2: Media Headlines on Murder Suicide \\ - Man under the bed' triggers murder/suicide \\ - Murder Suicide in Kitty... Man shoots girlfriend dead then takes own life over late \\ night visitor \\ - UPDATE: It's now Murder-suicide \\ - Suspected murder/suicide rocks Berbice \\ - Jealous husband hacks wife, her lover to death \\ - Murder/suicide rocks Parfait Harmonie \\ - Arrest attempt ends in murder/suicide: suspect slits throat after fatally stabbing Cop \\ - Guyana police: 2 dead in apparent murder-suicide
}

\title{
5. Conclusions and Strategies for Intervention
}

Suicide seems to be a problem solving strategy for the young, particularly those of the male gender, since the Guyana statistics confirm that those who commit suicide are often males, between the ages 15-44. This also holds true for murder-suicide. The challenge is therefore for a holistic approach to address coping and problem solving strategies amongst youth so that suicide is not seen as an option when intimate partner problems or any other kinds of problems occur. This has to start very early so that in schools', children understand how to reason and make informed choices. For this approach to be meaningful, it must be integrated within the curricula of the education system so that teachers understand how to teach to the issue of coping and problem solving as a life management issue and students especially youths are consistently able to translate these learnings into everyday life situations.

With religious organizations playing a dominant role in the life of all Guyanese, they are also an important stakeholder in working with persons on coping and stress management strategies. The East Indian male seems to be more vulnerable to all forms for suicide inclusive of murder-suicide and needs the attention of the religious and other cultural organizations and communities where they congregate. A targeted response for men is needed when one considers behaviour and character traits like abuse, alcoholism, depression, 
among others. Moreover, family and community from all indications see these behavioural traits but very often do not act in time since these matters are culturally perceived in the Guyanese contexts as family matters. Very often media reports indicate that families and communities are often left traumatized by these tragic events and this may be in part due to their guilt and perceived inability to have identified the problem before it culminated in the fatalities.

Importantly, the traditional definition of manhood in Guyana could also be a primary contributory factor when one summarizes the character traits identified in men who commit these fatal acts. How masculinity is defined and boys are socialized to manhood must be revisited since culture and religion can reinforce patriarchal systems and the perception of male dominance.

Whist there is an ongoing appeal for community and organizational support to address this ongoing issue of suicide inclusive of murder-suicide, these organizations can only provide support if they are equipped with the competencies to do so and would therefore require the support of the public health system. Thus whilst an examination of the various forms of suicide such as murder- suicide, the method of choice and other such elements are important to aid in an understanding of the phenomenon of suicide, the bigger picture to stem the tidal wave of suicide requires much more than indigenous community responses, there must be a holistic public health response which is cognisant of community health and the impact of any form of suicide on the family, the community and the nation.

\section{References}

Rosenbaum, M. (1990). The role of depression in couples involved in murder-suicide and homicide. The American Journal of Psychiatry, 147(8), 1036-1039. http://dx.doi.org /10.1176/ajp.147.8.1036

Barraclough, B., \& Harris, E. (2002). Suicide preceded by murder: The epidemiology of homicide-suicide in England and Wales 1988-92. Psychol Med, 32(4), 577-584. Retrieved from PubMed: US National Library of Medicine National Institutes of Health.

Daly, M., Wilson M., \& Weghorst, S. J. (1982). Male sexual jealousy. Ethology and Sociobiology, 3(1), 11-27. http://dx.doi.org/10.1016/0162-3095(82)90027-9

Emmanuel M. K., \& Campbell M. H. (2012). Commentary: Homicide-Suicide in the Caribbean. Journal of the American Academy of Psychiatry and the Law Online, 40(4), 469-471. Retrieved from http://www.jaapl.org/content/40/4/469.full

Henry, P. (2015). Agrochemicals, Suicide Ideation and Social Responsibility. Issues in Social Science, 3(2). http//dx.doi.org/10.5296/iss.v3i2.7926

Kates, B., \& Mauser, G. (2007). Would Banning Firearms Reduce Murder and Suicide? A Review of International Evidence. Bepress Legal Repository. Retrieved from http://law.bepress.com/cgi/viewcontent.cgi?article=6426\&context=expresso 


\section{Macrothink}

Issues in Social Science

ISSN 2329-521X

2016, Vol. 4, No. 1

Kivisto, A. J. (2015). Male Perpetrators of Intimate Partner Homicide: A Review and Proposed Typology. J American Academy of Psychiatry and the Law, 43(3), 300-312. Retrieved from http//www.jaapl.org/content/43/3/300.long

Maharajh, H. D., \& Abdool, P. (2005). Cultural Aspects of Suicide. The Scientific World Journal, 5, 736-746. http://dx.doi.org/10.1100/tsw.2005.88

Palermo, G. B., Smith, M. B., Jenzten, J. M., Henry, T. E., Konicek, P. J., Peterson, G. F., Singh, R. P., \& Witeck, M. J. (1997). Murder-Suicide of the Jealous Paranoia Type: A Multicenter Statistical Pilot Study. American Journal of Forensic Medicine \& Pathology. Retrieved from AJSP: Reviews and Reports.

Palmer, S. (1965). Murder and Suicide in Forty Non-Literate Societies. The Journal of Criminal Law, Criminology, and Police Science, 56(3), 320-324. http://dx.doi.org/10.2307 $/ 1141241$

Pan America Health Organization / World Health Organization (2012). Health in the Americas 2012 Edition - Regional Outlook and Country Profiles. Country Volume. Retrieved from http//www.paho.org/saludenlasamericas/docs/hia-2012-summary.pdf

Ramjattan Backs Decriminalising Suicide Attempts. (2015, August 7). Stabroek News. Retrieved from http://www.stabroeknews.com/2015/news/stories/08/07/ramjattan-backs -decriminalising-suicide-attempts/

Republic of Guyana. (2015). The Guyana Police Force Statistics on Murder Suicide.

Rosenburg, J. (2015). The Jonestown Massacre. About: Education. Retrieved from http:/history1900s.about.com/od/1970s/p/jonestown.htm

Smith, L. (2015, October 10). Man under bed triggers murder suicide. Guyana Chronicles: The Nation's Newspaper. Retrieved from http://guyanachronicle.com/man-under-thebed-triggers-murd ersuicide

Update: It's now murder-suicide. (2015, October 7). Demerara Waves: Riding on the crest of truth. Retrieved from http $/ /$ demerarawaves.com/2015/10/07/man-shoots-partner-to-death -attempts-suicide/

World Life Expectancy, World Health Rankings. (2014). Guyana Suicide. Retrieved from http://www.worldlifeexpectancy.com/guyana-suicide

\section{Note}

Note 1. Data for this study was adapted from the Guyana Police Force database, 2015 